\title{
Esteem of Territory and Country in Puglia (Italy) in Perspective of Sustainable Tourism: The Strategic Experiential Approach. An Apulian Case History
}

\author{
Arianna Di Vittorio \\ Associate Professor of Marketing, Dept of Economics, Management and \\ Business Law, University of Bari ALDO MORO, BARI , Italy
}

Doi: 10.19044/esj.2017.v13n28p452 URL:http://dx.doi.org/10.19044/esj.2017.v13n28p452

\begin{abstract}
The richness of tourism for Italian economy and employment depends on the use of environmental, artistic, historical resources, which the Country has available; but also on the realization of an optimal net of relationships and cooperations with the various regional, provincial and local institutions, based on a unitarian national vision of tourism development.

The touristic market has suffered some changes through the years, moving from a mass tourism to the global tourism, in order to get to responsible ecofriendly, sustainable tourism. In a so dynamic background, task of companies operating in this sector is that of interpreting the rising needs of consumers, aiming for quality and organization.

This paper's goal consists of bringing in surface the new perspectives of a tourism focused on the discoveyr of territory and the consequent development of country tourism' concept. Such trend puts the stress on a necessary interconnection between touristic, territorial marketing and policy of territory's maintenance and development.

In light of the changes that have influenced the relationships between touristic market and its own customers, the paper aims to offer a specific picture of relationship between tourism and sustainability, resting particularly on the marketing tools to give value to territory and supply the development of a sustainable tourism. The paper is supported by a practical case regarding the Manor farm in vineyard "Le Fabriche" located in Maruggio, by the Ionic coast of Salento (Puglia-Italy). Such land hosts some of the best accomodating structures, which manage to fuse together the development of its own economical activity with tradition and the peculiarities of the territory that hosts them.
\end{abstract}

Keywords: Tourism, sustainability, experiential approach, heritage 


\section{Aspects of sustainable tourism: economy, environment and society}

According to the concept of sustainable development given by WCED (World Commission on Environment and Development) in the Brundtland Report" in 1987, "the sustainable development is the development that satisfies the needs of the present day without compromising the capability of future generations of satisfying its own" (World Commission for Development and Environment, 1988). The previous ones are only some of the step definitions which have contributed to realize an awareness of duties and opportunities represented by the socalled "ecotourism or eco-friendly tourism".

It is possible to identify two different meanings of sustainability: weak and strong, both linked to the concept of resources' sustainability. They stand out in assets produced by man and natural assets. In the first are included all the works of human mind while the second, besides the natural resources meant in productive sense (agricultural, hunting and fishing products), includes also the natural resources usable under other points of view, such as the landscape beauty, the biodiversity, the artistic and cultural heritage.

According to the vision of supporters of weak sustainability, the desirable model of development should guarantee a stock of resources (human and natural) not decreasing till the following generation, what presumes the full sustainability of the two types of assets, so as to maintain stable in time the sum between human and natural assets, compensating the decrease of the one with the increase of the other. Such theory is deniable by the most confirmed strong sustainability, which presumes the complementarity between the two assets, trying to maintain stable each component of the stock, because the one's production depends on the other's availability. It is not allowable then an unlimited use of natural resources, because not replaceable like the human ones, but their impoverishment takes place to irreversible or reversible in long term processes.

To identify tools of support to the decisional process for the actuating strategies allows to guide the dynamic of touristic demand and offer towards the objectives of sustainability and an integrated vision of the aspects of economical and social development, besides consideration and protection of natural, artistic and cultural resources.

The subject has an important scope if we consider that the touristic system can become more and more complex for the interaction of factors

7In 1983, following a resolution of the General Assembly of United Nations, was instituted the world Commission for environment and development, which had the goal of elaborating a "Global Agenda for change". The Commission was directed by the Norwegian Brundtland, and in 1987 published a report, the Brundtland Report, which introduces the fundamental theory of sustainable development. 
such as the diversity and multiplicity of local offer's systems, the connection among the local government level and the overordered levels, the various levels of organization and representativity of interests present on the territory.

The certainty of the concrete possibility of realizing a sustainable development for the tourism is founded on the continuous disturbance between economical system and environmental system. The economical activities have a double impact on the environment: in primis when they use its resources, later on when they insert in it waste-products. Such requirements are interdependent and linked to environmental problems which must be integrated in the economical policy.

There are then possibilities for which an integrated strategy of global ecology is adopted, because if it is desirable the increase of income per head to increase one's own life level, it is nonetheless necessary not to identify the development with the only economical growth anymore, but with a higher care to life quality, whose parameters are identified in clean environment and social solidarity.

To promote the tourism sustainability means to realize the balance between a development of the sector respectful of natural resources' limits and careful to their actual capability of regeneration and an adequate commercial return.

In fact, the touristic sector, being based on environmental, cultural and social quality of the context where it develops its own supply system, risks, if not correctly managed in terms of safeguard of such quality, to damage its own base of resources at the point of becoming economically and socially unsustainable.

From a series of either legislative or economical analysis, it is possible to deduce the principal characteristics of sustainable tourism:

-durability: the touristic activity is not founded on the short-term growth of the demand, but on the middle and long-term effects of the adopted touristic model, trying to put in harmony the economic growth and the maintenance of environment and local identity;

-shaping and respect of environment: shaped tourism in time to reduce the effects tied to the seasonality and in space, locating the capacity of territory's reception and limiting the flow of tourists in function of physical characteristics of places;

-integration and diversification: the touristic offer must be the natural result of local resources. The tourism can not be an element unrelated to the place identity, but an element integrated to the cultural and economic richness in itself. The touristic model is open to the surrounding territory so that the natural spaces of close localities take part of the same touristic supply; 
-planning: implies a careful analysis of the present conditions and future perspectives, together with taking into account, at the moment of consideration, the different variables that intervene in the touristic system;

-economical vitality: it is fundamental not to give up to economic vitality and the research of wellness of local community and to dynamicity in time of investments;

-participation: because all the subjects must be involved in decisional processes regarding the territory's developemnt and cooperate in its realization.

The tourist development has the foundation of its own long-term success precisely in the capability of managing the economical, social and environmental components in an integrated way, promising the respect of:

-environment: we must acknowledge that the environmental qualities of a tourist locality are among the first and most fragile elements of attractivity of tourist flows and each intervention compromising its quality degrades the context determining in the medium and/or long term a decrease of the tourist flow itself;

-society: to guarantee the conditions of human wellness, equally assigned for classes and genres;

- economy: the tourist developement can determine social and environmental costs superior to the economical advantages in medium and long term. The economical compatibility presumes a criterion of rationality in choices that unites to the creation of economical value for the operators or sector, the protection, appreciation and conservation of natural, cultural and social environment. A negative impact can take place when the local economies depend in a too exclusive way on the tourist activities, giving place to the so-called "tourist monocultures". This situation can destabilize the whole economy of destination that depends on external, even very volatile, factors such as the preferences of tourists that join to the unpredictable weather-climatic variables.

The relationship tourism-environment is complex: from one side the tourism depends on the environment to attract tourist flows, from the other the tourist activity can impact on the environment damaging it in a more or less serious and permanent way. The principal negative impacts are to bring back to the energy and water consumption and to the uncontrolled management of urban garbage.

To the relevant aspects at local leves are added the environmental problems at global scale such as the loss of biodiversity, the decrease of ozone layer and the weather change. For this reason it is necessary an adequate managemet of the verifiable risks connected to the tourism and to the physical impacts on environment and artistic and cultural assets. 


\section{The country and food-wine tourism: esteem of an heritage}

In the last decades the Italian country areas, and particularly Apulian, have been interested by deep transformations that have produced a remarkable change of their traditional economical-social structure. Such areas have acquired a growing importance, due to the change of life styles and consumptions. To form the country space contribute more and more economical activities such as tourism, commerce, craftsmanship.

The today life styles, characterized by a persistent frenzy, and a psycophysical condition put under continuous pressures, have brought to the research of a physical wellness and of a strict contact with territory and consequently to the direct esteem of natural resources and purchase of biological products.

One of the immediate effects has been the enlargement and reinforcement of country tourism supply and of its two principal components: agritourism and local food farming products. These sectors through the last two decades, have been object of a growing attention from the communitarian and national politics towards the country areas. In particular, to them has been assigned a strategic role in favouring the start and strengthening of sustainable developement's processes, of local character, managed by operators present in the intervention area founded on either tangible (environment, architecture, typical productions) or intangible (culture, traditions, history) resources.

It is, then, necessary to analyze the country tourism phenomenon, catching its real roots. Simonicca (2004) includes the country tourism in the category of "alternative tourism" or with sustainable goals, in which the tourist has a comparison with other sociocultural or natural environments, different from those where he lives.

The European Commission identifies several types of rural areas according to the integration with the economy of its own state: integrated, intermediate and remote rural areas. Such distinction comes from the necessity of locating a "rural space" distinguishing it from the city one. In fact rural derives from the latin word rus, which means "cultivated country".

The "integrated areas" are charcterized by the presence of coordination of all sectors of economy (primary, secondary and tertiary), with the risk of becoming residential areas. The intermediate areas are far from the urban centres and in them are developed primary and secondary sector, while the remote areas have an economy based on agriculture, infrastructures and minimal services (mountain areas). These territories present some features that at the moment the European Unity is reevaluating in the field of projects of rural development, in which tourism is one of the elements object of appreciation (www.retenaturale.it). 
Minca (2001) says "The touristic space has unclear nature. First of all, tourism lives in an imaginary space, equipped with the mental maps that crowd the phantasies and collective and individual desires. Secondly, it organizes materially its own context, integrating it thus with the geographic space" (p.89). For this reason, at a tourist level, it is necessary to identify the localization of potential tourist destinations, defined on the basis of place characteristics, natural and cultural resources, and the diffused image of such places.

The country tourism is esteem and safeguard of territorial and environmental context where the activity takes place, based on rural accomodating structures that are grounded on technologies and activities, with the aim of revitalising the area in question.

In the last years in the rural areas, especially the Italian ones, have been born many initiatives of appreciation of the rural territory, of agritourism and of local food farming products, allowing the raise of a phenomenon linked to the rural tourism: the food-and-wine tourism.

A form of cultural, thematic, integrated and sustainable tourism, where the spirit of the place is tasted in the plate and is examined in the visit of territory and of production company. If well designed, managed and experienced, it is a real resource for the economy and the sensorial discovery of geographic places (Croce \& Perrini, 2010).

At the beginning the food-and-wine industry was accessory of the various forms of tourism but later on it has assumed its own precise identity, becoming object of a form of tourism in itself. It supports the preservation and esteem of agrarian territories and couples the rural culture, through the knowledge of agriculture and gastronomy, by the tasting of wines or other typical products.

The food-and-wine tourism rises and develops itself as niche tourism (age included between twentysix and fortyfive and middle-high social level) which appreciates calmness, contact with nature, typical genuine food, freedom of movement, knowledge of agriculture and food's origin. The tourist thus can know a productive model which aims to realize a quality product in respect of the environment.

In Italy the food-and-wine tourism is a phenomenon which dates back substantially to the Nineties; earlier in fact it was not possible to speak about an organized offer, but about sporadic events that still had the taste of town festival.

At the moment in Italy, the only law made to give value to the territories with wine vocation is the law 268/99 published on the "Gazzetta Ufficiale" nr.185 of August 9th 1999 whose principal goal is to institutionalize the so-called "wine roads" that is signalled and promoted paths with specific billboards, along which it is possible to find natural, 
cultural and environmental values, vineyards and cellars of farming companies, individual or associated open to public; they constitute the tool through which the wine territories and the related productions can be divulged, commercialized and used in form of tourist offer.

The food-and-wine tourism is disciplined by "Origin's Denominations" that guarantee the real naturalness and typical characteristic of the product. As regards the Origins' Denominations for wines, the most known and used are: DOCG (Denomination of Controlled and Protected Origin); DOC (Denomination of Controlled Origin); IGT (Typical Geographic Indication). All these three denominations are disciplined by law 164/92 (www.aicig.it, Associazione Italiana Consorzi Indicazioni Grafiche).

It is by now stabilized the awareness that tourism represents a strategic factor of growth and one of the most important voices of economy in Countries, regions, localities that have resources to which give value and are able to create, programme, manage, safeguard and requalify their tourist product.

The extraordinary success observed with millions of "agro-winetourists" is founded on several factors and on their careful combination. In particular, we identify the following factors which have brought the business estimate to more than 5.000 billions per year:

- Strong demand of "food quality" and then of wine with "recognizable signs" of such quality;

- Growth of dimension of "pleasure" linked to quality wine to which the participants to the Movement have been able to give efficient answer even through communication's activities;

- Strong demand of "eco-compatible area": it is not a coincidence that the Movement has been developed starting from the better preserved vineyardareas and with one of the most interesting landscapes of the country;

- Strong link between "wine production" (that is agricultural) and local history, tradition and culture (food-and-wine and not);

- Strong demand of direct relationship with the producer, high spirit of "service to the client" and willingness to the hospitality in cellar.

All these are aspects that indicate the insurgence of a complex demand, where the material, intangible, service, symbolic elements are strongly intersected and require a careful, continuous and creative planning.

Pastore (2009) concludes "The food-and-wine tourist is a person who is willing to move from his own residence locality with the aim of reaching and understanding the culture of a destination known for a valuable food farming production, entering in direct contact with the producer, visiting the area destined to the processing of the raw matter and to the following 
packaging, tasting there and stocking himself personally with the speciality" (p.94).

\section{The strategic experiential approach: the new vision of traditions and places}

The processes put on act by globalization, the new technological tools and the progress in infrastructures and means of transport, have overthrown the distances among the markets (Farinet \& Ploncher, 2008), creating two trends: one linked to mobility of individuals who visit and discover places to them unknown and far away from their residence, the other linked to the mobility of resources.

Such phenomenon has positively influenced the diffusion of typical products of a territory, which have passed from a totally local market to an international one, increasing their popularity and spreading the culture of which they are witnesses of excellence. Thus benefits have been born, either for the commerce, which has spread its markets of way out, or for the tourism. The knowledge of new products in fact encourages the curiosity, for those who have purchased them, to visit the place of origin.

The typicity of a territory depends on its capacity of passing down to products and services the value of some factors that distinguish it, like the environmental dimension, the cultural dimension and the social dimension that represent tourist resources to safeguard.

The first emerges from the appreciation of natural resources of a territory, such as weather, landscape, flora, fauna, rivers etc; the second from the resources created by man through history, such as monuments, museums, events, etc; while the third emerges from the esteem of resources like folklore, local traditions, customs (Scipioni \& Vecchiato, 2009). Such resources represent the attractive factor of a place, the reason that pushes people to move and spend some time in a place rather than in another. To make the place pleasant and attractive, the only present resources are not enough, but a series of elements and conditions are necessary, that enrich the offer of a locality, in compliance with the principal resource and territorial identity.

The typical resources of a place must be at the same time either shared, that is acknowledged as values by all the involved subjects and inserted in an action of integrated and coherent communication, or distinctive, capable actually to make the place unique and different, and to stimulate the tourist demand.

Such demand has suffered a change, orienating itself strongly to the research of experience and of rediscovery of products and brands tied to territory, whose challenge will be that of identifying the elements able to 
satisfy these new needs and to reward value to its offshoots, that is local brands and products.

It deals then with identifyinf which are the paths that can be undertaken to increase the value of territory and local products.

The elements characterizing a territory can be linked either to factors of touristic attraction, or to the production of a given category of goods, typical of the place. In this second case territory can give place to a "productive district" (Rullani, 2002; Becattini, 2012) where companies center specialized in different steps of the chain, but even to a commercial district, seat for outlet and selling points.

In some cases, the area characteristic, typical of one good's production, adds up to one or more factors of touristic attraction, enriching with value the total offer that, in order to create demand, can thus use either one or the other element.

It is evident the existence of a link among territory, the touristic offer and the commercial offer, whose respective actions and decisions determine a synergistic system of forces and value.

The decisions taken in the scope of territory's development influence the elements about which the actors of tourist offer will have to ground the construction of their proposal and, at the same time, influence the stimulus on which the dealers will be able to focus, in order to valorize their offer, that in its turn will be able to represent a source of competitive advantage for territory.

A developed commercial offer can have a positive impact on territory, above all if it is developed coherently to the factors of tourist offer that are able to transform the buyers/hikers in tourists. The territory will be then positively influenced by the development of a commercial offer and of a coherent and coordinate tourist offer, that allows it to acquire a distinctive image, transferable to its typical products that, even thanks to the associations with the territory, will be able to increase their value in the eyes of the consumer (Keller, 2013).

It would be then correct to affirm that tourism is potentiated by commerce, which contributes to create purchase and consumption experiences, like for example the production of local handicraft or wineand-food routes that attract a high number of tourists-visitors. Such relationship between tourism and trade is realized because "the purchase" is one of the most pervasive activity practised by tourists during their length of stay: it is estimated in fact that the expenditure tied to this kind of activity represents about one third of the total travel expenses (MacCannell, 2009).

The composite need that is read in the consumer and tourist purchase behaviour, often however does not find feedback in the tourist promotion of a territory, within which the connection with the commercial offer is 
missing. It would be instead necessary to develop an action able to valorize even such offer so that it is support to the traditional tourist flow or that recalls new targets of visitors, creating more value not only for tourist operators and dealers, but even for the consumer himself.

Then, the offer of a determined territory, able to move masses, is composed of two factors: the tourist one, in the most common sense of the word, and the commercial one. The two offers are not alternative but complementary, part of a unique system that should tend to the realization of a sole objective: to increase the economy of the place and the flow of people, valorizing consequently the territory. If commerce links its value offer to the elements of tourist attraction and then of typicity that distinguish the area, it will be possible to speak no more about commercial offer and touristic offer, but about offer of territory.

From this circumstance it results that the tangible and intangible attractivity factors of territory, developed and developable, of touristic and commercial offer, form the territory's identity. The communication activity will have the task to let the potential viewers perceive a distinctive image, able to differentiate territory and the resulted by it products.

If tourist offer, commercial offer and territory represent then a system able to create value for different actors, it deals with understandig how to activate such system, in order to create a virtuous circle among the three elements.

It is possible to identify three principal instruments to reach this goal:

- Creation of tourism and purchase experiences;

- Realization of events;

- Use of Internet as means of support.

The experiences of tourism can be generated either in relationship with the commercial offer or binding them to factors of tourist offer, thanks to the realization of new coherent proposals to territory's development, turned to magnify their typicalities, or innovative and finalized to give origin to new occasions of visit and expenditure.

Pine and Gilmore (1999) define the experience as the fourth form of economical offer, distinguished from services, from products and from commodities.

In the purchase of a service, the consumer in fact pays the compensation for a set of intangible attributes that surround the purchased good, but in the purchase of an experience he/she pays to spend his/her time, living a set of memorable events, created to involve him/her and create a deeper relationship. The analysis of expenditure's behaviours and purchase's motivations tied to experience have been studied by marketing. It can be noticed in fact a propension toward marketing strategies that link brand, product, service and place to the emotional sphere of consumer, using 
the creation of significant experiences as competitive stimulus (Carù \& Cova, 2011).

This stimulus can be used also in marketing actions directed to the development of territorial offer, creating purchase routes that focus the experience on the existing link between product and territory. The actions of experiential marketing in this sense can be adopted either by commerce or by tourist offer, with the aim to create in both cases a greater flow of visitors/consumers.

The tourist offer, that for its nature itself has a strong link with the experiential factor, can be enriched by the concepts introduced by marketing experience, in order to exploit the tipicality's resources of tourist destination.

The second means that can be used to activate the virtuous circle of tourism-commerce-territory is the development of events which animate the territory and emphasize its characteritics and tipicalities. The possible events are numerous and can be tied to history, culture and traditions of the place, merging in a harmonious way with the local community where they take place (Kotler, 2003).

Even in this case, the means can be linked either to elements of tourist offer or to those of commercial offer and the creation of events, able to exploit both, using territory as a fulcrum, will generate greater value for the viewer thanks to the action of mutual elements of attraction.

For the territory's development, the events grounded on elements of tipicality are interesting, difficult to replicate in other places and that then give origin to a unique and distinctive offer, which visitor can consume only going to that specific location.

Internet intervenes in the virtuous circle because it acts either as information channel in the choice phase of tourist destination, or to give voice to the experience in the moment after the trip.

All this contributes to the development of tourist and territory offer, but at the same time it creates value for commerce, that exporting its products increases its income and is reflected positively on territory that might be recognized and appreciated for its tipicalities.

4. The strategic approach of accomodations and integration with the environment: analysis of resources and Swot-Pest of Masseria in Vigna "Le Fabriche" in Maruggio (Taranto - Puglia)

An accomodation targeted to the integration with territory and its development, before even being able to take decisions of strategic importance, must be perfectly aware of the peculiarities and elements characterizing the surrounding territory. 
It is on this presupposition that the plan "Le Fabriche" begins at the end of 90s in Maruggio (Taranto, Italy). Along the coastal area of Maruggio, called Campomarino, the Ministry of the Environment located a priority habitat, represented by coastal dunes with junipers and six habitats of Community interest, important because they contribute significantly to the vegetable biodiversity.

The project consists in the possibility of working with autochthonous vines, pointing to quality. Biological cultivation and research on vines and vineyards, through cooperations with the best agronomists, oenologists and Universities. The attention is focused on the new spaller systems that are placed side by side with grapes such as Primitivo, Negramaro and Malvasia nero; systems that lodge two thousands different selections of Aglianico.

Thus Emmaus is born, a wine already rewarded in 2005 coming from winemaking of grapes deriving from vineyards poles apart: one belated and the other premature, the first giving great wine structure and the second taking fruity notes.

Another won challenge is the $100 \%$ biological cultivation of grapes, thanks to a constant monitoring of the bunches and to a precipitous mild climate and mitigated by the salty breezes of the sea. The followed business philosophy is that of rewarding the naturalness.

To the care of the vineyard are added six hectares of olive groves, with centuries-old plants of native varieties such as Cellina and Ogliarola, precociously harvested avoiding the falling to the ground of the drupes, obtaining thus an extra virgin olive oil called Olivaro (name deriving from the ancient land where the olive trees are located).

The farm Le Fabriche becomes a project in continuous development and expansion, focusing on the short chain, on the model of the classical and estimable Bordeaux Châteaux.

In 2007 gets started the project of a modern and refined relay inside the seal. Among the rows of vines and the olive trees, around twenty suites have been built, which offer to the guests a living experience in contact with nature and absorbed in the surrounding environment.

The constant search of quality and naturalness is reflected even on the slow food managed by specialised personnel and driven by the Apulian tradition. Leitmotiv of the culinary experience of Le Fabriche is constituted by the extra virgin olive oil and by the wines of the farm, biological products at zero kilometer.

It is a well defined project, but also a constant challenge with conflicting realities that limit the principle of territory's respect and its development, preferring financial alternatives targeted at "mass" rather than quality investments. 
The SWOT analysis has been worked out and used in this paper to evaluate the competitive profile of the company in question, examining then the endogenous strengths and weaknesses, as well as the opportunities and threats coming from the external environment (Fig.1).

Once processed the SWOT analysis, it is necessary to sketch the scenario in which the entrepreneur acts to identify the variables that can be relevant in the company decisional process.

Thus, the PEST analysis intervenes, analyzing some Political, Economical, Social, Technological variables that manage to sketch the scenario of the macro-environment where the company acts (Fig.2). Such analysis allows to identify which variables can be relevant in the company decisional process, in the strategic and operative choices of the company. From the present analysis it is possible to understand the threats that impend and the opportunities to take advantage of it suddenly.

Fig.1 - SWOT Analysis Farm in vineyard "Le Fabriche", Taranto (Puglia, Italy)

\begin{tabular}{|c|c|c|}
\hline $\begin{array}{l}\text { The } \\
\text { elements's } \\
\text { strategic } \\
\text { scope }\end{array}$ & & \\
\hline Inside & $\begin{array}{l}\text { Strengths } \\
\text { - Diversification of entrepreneurship through } \\
\text { the two companies formation: TOURIST } \\
\text { SERVICE SAS and LE FABRICHE } \\
\text { agricultural company srl; } \\
\text { - integrated and biological agricultural } \\
\text { production of wine and olive oil; } \\
\text { - utilization of short chain; } \\
\text { - high quality of host locals: } \\
\text { - assistance and direct contact with the } \\
\text { customer; } \\
\text { - high reputation at web and press; } \\
\text { - presence in social networks; } \\
\text { - close interconnection between agricultural } \\
\text { and tourist activity; } \\
\text { - strong promotion activity; } \\
\text { - participation in initiatives and events; } \\
\text { - website optimized for high traffic due to } \\
\text { greater online visibility; } \\
\text { - comfortable structures; } \\
\text { - maximum cordiality; } \\
\text { - professionalism in every offered service; } \\
\text { - emotion and memory in the customer; } \\
\text { - cooperations with research institutes; } \\
\text { - parking area; }\end{array}$ & $\begin{array}{l}\text { Weaknesses } \\
\text { - Seasonal tourism } \\
\text { (opening from Easter to } \\
\text { the end of October, the } \\
\text { peak of bookings in } \\
\text { August); } \\
\text { - lack of pool for the } \\
\text { satisfaction of } \\
\text { Anglosaxon guests; }\end{array}$ \\
\hline
\end{tabular}




\begin{tabular}{|c|c|c|}
\hline & $\begin{array}{l}\text { - mktg management directed by } \\
\text { entrepreneur; } \\
\text { - panoramic terrace; } \\
\text { - services with territory's partners (equipped } \\
\text { beach, horse riding excursions, guided visits } \\
\text { in the interest places, sailing and diving } \\
\text { courses, boat trips, excursions, transfers from } \\
\text { and to airports) } \\
\text { - internal services (lounge bar, restaurant, by, } \\
\text { wine and oil tastings, cooking classes, spa } \\
\text { treatments in the room, free wi-fi in the } \\
\text { common areas). }\end{array}$ & \\
\hline Outside & $\begin{array}{l}\text { Opportunities } \\
\text { - Proximity to the sea and to the principal } \\
\text { sites of interest in Puglia; } \\
\text { - offer aimed to different market segments ( } \\
\text { meeting, presentations, events, weddings); } \\
\text { - recovery of native vines; } \\
\text { - technological progress that allows the } \\
\text { qualitative improvement of the products and } \\
\text { cost reduction; } \\
\text { - the affirmation of new forms of non-mass } \\
\text { tourism; } \\
\text { - attractive destination. }\end{array}$ & $\begin{array}{l}\text { Threats } \\
\text { - Presence of business } \\
\text { lobbies; } \\
\text { - environmental } \\
\text { contaminations; } \\
\text { - poor means of } \\
\text { landscape protection. }\end{array}$ \\
\hline
\end{tabular}

Fig.2 - PEST Analysis Farm in vineyard "Le Fabriche", Taranto (Puglia, Italy)

\section{POLITICAL}

- Air industry liberalization and deregulation

- Weakness of public policy for the environment of touristic destinations - Always smaller availability of public resources for infrastructure investments - Biomass market and industrial agrochemical speculation

- Wild industrialization policy

- Poor policies of protection of landscape and of cultural and environmental heritage - Internal conflicts with terrorism risk - Increase of presence of immigrants in the south Italy areas

- Development of organic food concept

- Research of tourist destinations not more mass but élite.

\section{ECONOMICAL}

- Period of crisis that creates a stall state of tourist flows to deal with bid Low Price strategies

- Attention to sustainable tourism and to resource management

- Constant growth of world tourist market 


\begin{tabular}{|c|c|}
\hline 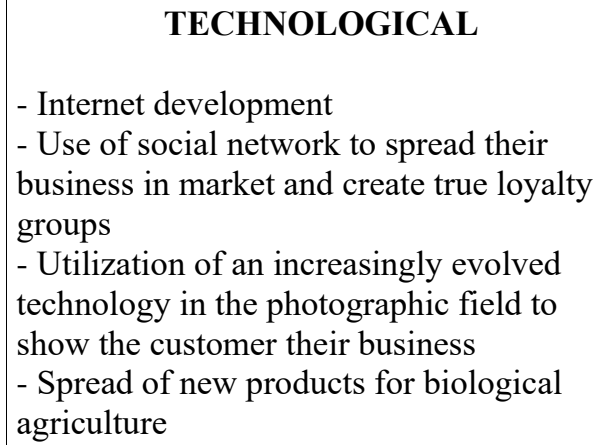 & $\begin{array}{l}\text { SOCIAL } \\
\text { - New conception of tourism not only an } \\
\text { end in itself, but characterized by sensory } \\
\text { experiences such as: yoga, trekking, diving, } \\
\text { food and wine } \\
\text { - Growth of Internet users' number for } \\
\text { research of reviews and tourist destinations } \\
\text { - Greater attention to ecological- } \\
\text { environmental problems } \\
\text { - Research of psycho-physical wellbeing }\end{array}$ \\
\hline
\end{tabular}

The PEST analysis presents a macro-environemnt with most favored features for the development of either touristic or agricultural activity of the company "Le Fabriche": 100\% organic cultivation of the grapes in the vineyards follows the philosophy that tries to reward the naturalness.

Reason that is repeated in the PEST analysis is the tie between the physical surrounding environment and the protection of tourist destination. This counteracts with a policy not able to protect the territory, at the expense of the activity being carried out by "Le Fabriche".

The threat of environmental and marine pollution, with the proximity, though marginal, of the steel company Ilva in Taranto, or the need of business lobby to change the typical cultivations characterizing territory, installing solar panels or wind farms without considering the presence of business activities, able to improve also the territory, are conditions strongly influencing the development of the business activity in question, hindering the principal mission of entrepreneur; integration of tourist activity with territory and improvement of surrounding landscape.

Definitely, the reason of the success of Farm in vineyard "Le Fabriche" is to look for in the emotions: a tourist characteristic that changes over time in a baggage inside his memory. The contact with the manager, with his habits, with territory, are all pulses that act in the emotional sphere of customer.

\section{Conclusion}

The tourism sector is living a remarkable change due above all to the fluidity of the market, to the easiness with which passengers can access information and products on the web and to the need of creating a value added to his own tourist experience.

The SWOT analysis about the relay strategies and the PEST analysis about the marco-environment, together with a deepening of the concept of tourism sustainability, have allowed to identify and point out the present 
synergies between the tourist activity and the valorisation of the host territory.

The integrated and biological agricultural production of wine and olive oil, and the use of the short chain allow to valorize even the tourist activity that integrates perfectly with the surrounding environment without altering it.

"Le Fabriche" takes on a role, similar to that of the storyteller, that offers a personalized stay and customized products through stories, suggestions and tales typical of the Salento territory. Amazement, involvement and protagonism are the best actuated strategies, which allow the customer to become witness.

The host of "Le Fabriche" has the possibility of tasting food realized with dishes at zero kilometer for a healthy eating, which put the stress on the typical productions of the territory. The food and wine has in the last years taken a central role in expectations and motivations of travelers themselves, to imagine a process of "capitalization" of local food and culinary specialties to consider real tourist attractions, able to move a target of travelers called "foodies". Food thus becomes merging point between the authenticity of the territory and the tourist, more and more eager of genuine, participative proposals, strictly tied to the specificity of the territory that he/she visits.

The business activities and the surrounding environment are connected by a thin and firm wire that creates a relationship of interdependence: Italy is among the few countries in the world to be sanctioned in its constitution the principle of protection of landscape and cultural heritage, but there is chasm between the enunciated principles of safeguard and protection and the reality of degradation of surrounding space, because there are no valid tools of defense and sensitization of landscape respect.

The growth of a Country must be considered even rating elements such as air quality, citizens' health, education, richness of social relationships. The companies should be valued depending on their capacity of producing wellness to territory that hosts them in terms of environment's safeguard, preservation of biodiversity and of citizens' quality of life.

\section{References:}

1. AA.VV. (1988) World Commission for development and environment, The future of all of us. Milano: Bompiani.

2. Aaker, D. A. (2002), Brand Equity. La gestione del valore della marca. Milano: Franco Angeli.

3. Aaker, D. A., Keller, K. L. (2010), Valutazioni dei consumatori della brand extension, Giornale di Marketing, 51. 
4. Aaker, D. A., Keller, K. L. (2014) , Gestione della brand equity: l'impatto di molteplici estensioni di marca. Milano: Franco Angeli.

5. Aaker, D. A., Keller, K. L. (2015), Interpretazione repliche interculturali di ricerca brand extension. Milano: Franco Angeli.

6. Baumann, Z. (2003), La società sotto assedio. Bari: Laterza.

7. Becattini, G. (2012), la coscienza dei luoghi. Il territorio come soggetto corale. Roma: Donzelli Editore.

8. Carù, A., Cova, B. (2011), Marketing e competenze del consumatore. Milano: Egea.

9. Cinti, D. (2014), Turismo rurale e progetto di paesaggio. La Valtiberina toscana per un turismo culturale e naturale sostenibile. Milano: IBS.

10. Cresta, A., Greco, I. (2011), Luoghi e forme del turismo rurale. Evidenze empiriche in Irpinia. Milano: Franco Angeli.

11. Croce, E., Perrini, G. (2010), Il turismo enogastronomico. Progettare, gestire, vivere l'integrazione tra cibo, viaggio e territorio. Milano: Franco Angeli.

12. Fabris, G. (2013) Il nuovo consumatore: verso il post moderno Kapferer, J. N. (2007), Strategic brand management. Londra: Kogan Page.

13. Kapferer, J. N.(2009), Reinventare la marca. Milano: Franco Angeli.

14. Keller, K. L. (2013), Conceptualizing, Measuring, and Managing Customer-Based Brand Equity. Journal of Marketing, 57(1), 1-22. doi:10.2307/1252054.

15. Keller,, K. L., Busacca, B., Ostillio, M.C. (2014), Gestione e sviluppo del brand. Milano: Egea. Ed.or.: Strategic Brand Management (Keller, K. L., 2003).

16. Lo Surdo, G. (2013), Il marketing delle nuove vacanze. Comunicazione e mezzi di promozione del turismo rurale, enogastronomico, della natura, del wellness. Milano: IBS.

17. Minca, P. (2001), Spazi effimeri: geografia e turismo tra moderno e postmoderno. Padova: CEDAM.

18. Pastore, R. (2009), Il marketing del vino e del territorio: istruzioni per l'uso. Milano: Franco Angeli.

19. Pine, J.B., Gilmore, J.H. (1999), The experience economy. Boston: Harvard Business School Press.

20. Rullani, E. (2002), Economia della conoscenza. Creatività e valore nel capitalismo delle reti. Roma: Carocci.

21. Simonicca, A. (2004), Turismo e società complesse. Saggi antropologici. Milano: Meltemi Editore. 
22. Scipioni, A., Vecchiato, G. (2009), Marchio d'area: strumento di competizione turistica. Milano, Franco Angeli.

23. Srivastava, K., Shocker, A. (2011), Brand Equity: a perspective on its meanining and measurement. Cambridge, UK: Marketing Science Institute. 